\title{
Transfer Function Models for Forecasting Domestic Water Use
}

\author{
Ahmad, M. I. \\ Sultan Qaboos University, Muscat, Oman \\ idrees@squ.edu.om
}

\begin{abstract}
The ability of transfer function models to forecast domestic water use is investigated. Five years monthly time series data on domestic water use, total rainfall and average temperature from Muscat was taken for this study. The transfer function models aim to describe the relationship between input and output systems using a ratio of the polynomials representing the Laplace Transforms of the output, input and the noise in the system. Total rainfall and average temperature were considered as the input series and the domestic water use as an out series. The input series were pre-whiten using Seasonal Autoregressive Integrated Moving Average (SARIMA) models which were identified by Sample Autocorrelation (SAC) and Partial Sample Autocorrelation (PSAC). Four preliminary transfer function models were postulated to describe the output series. The graphs of Sample Cross Correlation (SCC) of water use with rainfall and temperature were made. The final transfer function model was identified by investigating the Residual Sample Cross Correlation (RSSC) which had the form SARIMA(1,1,1)x(1,1,1). This model was then used to generate twelve months out of sample forecasts. The accuracy of forecast error was assessed by mean absolute deviation (MAD), mean square error (MSE) and mean absolute percent error (MAPE). All of these measures had reasonably small values which were $0.105,0.013$ and $1.37 \%$ respectively.
\end{abstract}

Keywords: Forecasting, Domestic water, Seasonal Autoregressive Integrated Moving Average

\section{Introduction}

Modeling and forecasting domestic water use had received a considerable attention in recent literature on the subject (Nazario, 1993; Khtri and Vairamoorthy, 2007; Agthe and Billings, 1980; Hutton, 2003). Most of the empirical investigations made rely on the multiple regression models by considering rainfall and temperature as covariates. The normal regression, however, assume that the covariates should be predetermined while both these covariates are random variables. This makes it very difficult to apply ordinary least squares estimation and inference methodology on the regression models. This study attempts to investigate the adequacy of transfer function modeling technique as a means of more appropriate representation of the observed dynamic response characteristics of water use changes over time. The derived model is developed for short term forecasting based on monthly water use data in urban areas of Muscat the capital of Oman in order to ensure the adequate and sustainable water management for the city that is growing very rapidly. These data were taken from (Al-Oaimri and AlHadrami, 2013; Ministry of National Economy, 2006-2010) and the characteristics of the data are illustrated in figure 1-3 which shows monthly aggregate municipal water use, average monthly temperature and rainfall from 2007 to 2011. An annual growth in both average annual use and in seasonal variation as well as a large variation in summer water use from one year to the next is evident from the data. A regular pattern of seasonal variation which is temporarily interrupted by the occurrence of rainfall is evident over the summer. The nature of these interruptions is most clearly seen in Figure 3, which illustrates the effects of two isolated rain-falls in June 2007 and 2010. Each time that there is rainfall, the water use is reduced immediately, and then it gradually resumes its regular seasonal pattern. That is why the temperature and rainfall were taken as input to derive the proposed forecasting model.

\section{Transfer function models}

The concept of transfer function derives from the idea of variations in the independent or input variables transferring into variations in the dependent or output variable. Transfer function models are logical extension of univariate time's series models which utilize only the past history of the series for modeling. Assuming that $\mathrm{x}_{\mathrm{t}}$ and $\mathrm{w}_{\mathrm{t}}$ are the properly transformed series so that they are both stationary. The output series $w_{t}$ and the input $x_{t}$ are related through a general model (Maidment, Miaou and Crawford, 1985; Bruce \& O'Connell, 1993) given as below.

$\mathrm{W}_{\mathrm{t}}=\mathrm{v}(\mathrm{B}) \mathrm{x}_{\mathrm{t}}+\eta_{\mathrm{t}}$, where $\mathrm{v}(\mathrm{B})=\Sigma \mathrm{v}_{\mathrm{j}} \mathrm{B}^{\mathrm{j}}$ 
Where $v(B)$ is referred as the transfer function and $\eta_{t}$ is the noise series of the system that is independent of the input series $x_{t}$. The coefficient of the transfer function, $v_{j}$ are known as the impulse response weights. The transfer function is said to be stable if the sequence of these impulse response weights are absolutely summable. Thus in a stable system, a bounded input always produces a bounded output. The transfer function is causal if $\mathrm{v}_{\mathrm{j}}=0$, for $\mathrm{j}<0$. Thus in a causal model the system does not respond to input series until they have been actually applied to the system. Thus the present output is affected by the systems input only in term of its present and pass values. In practice a causal and stable model is considered.

\section{Figure 1: Monthly water use distribution over five years from 2007-2011}

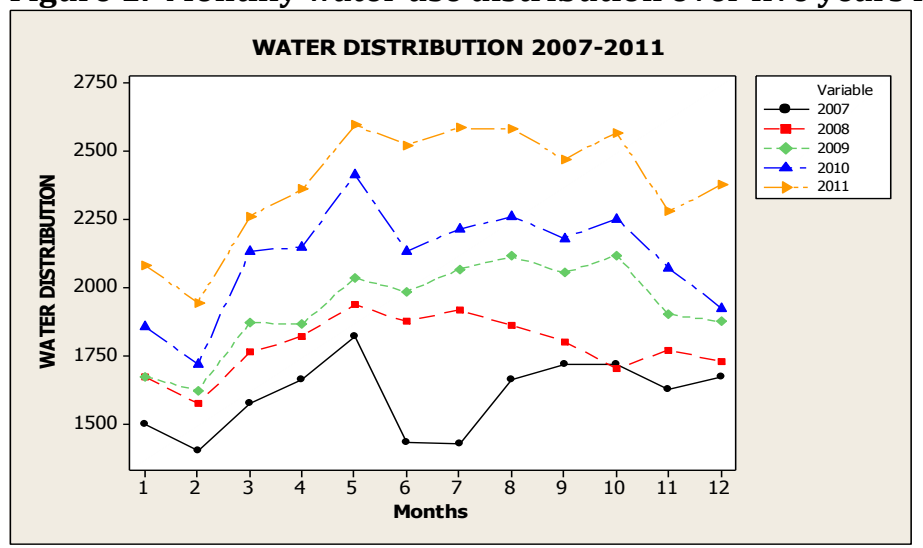

Figure 2: Monthly average temperature over years from 2007-2011:

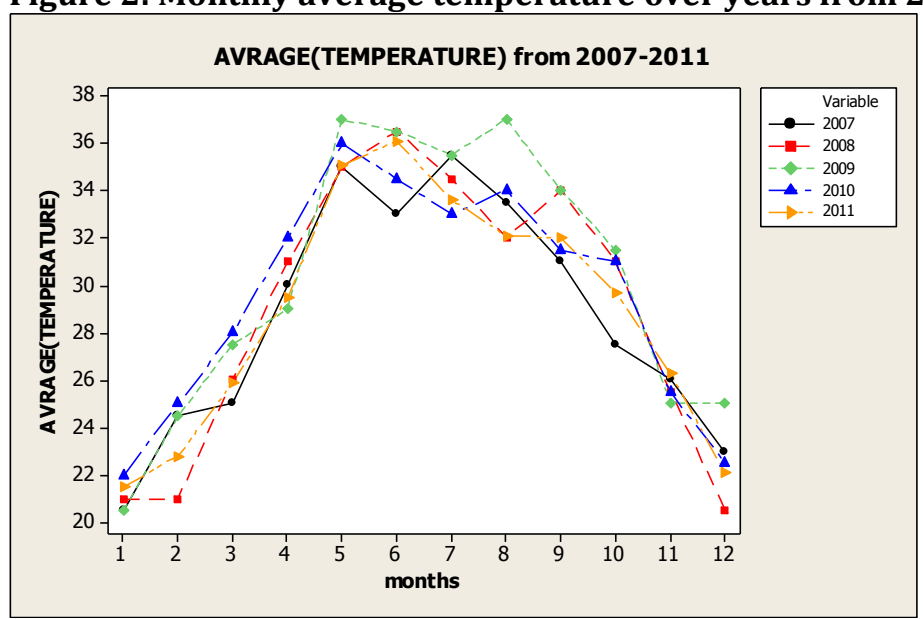

Figure3: Monthly rainfall over a year's 2007-2011:

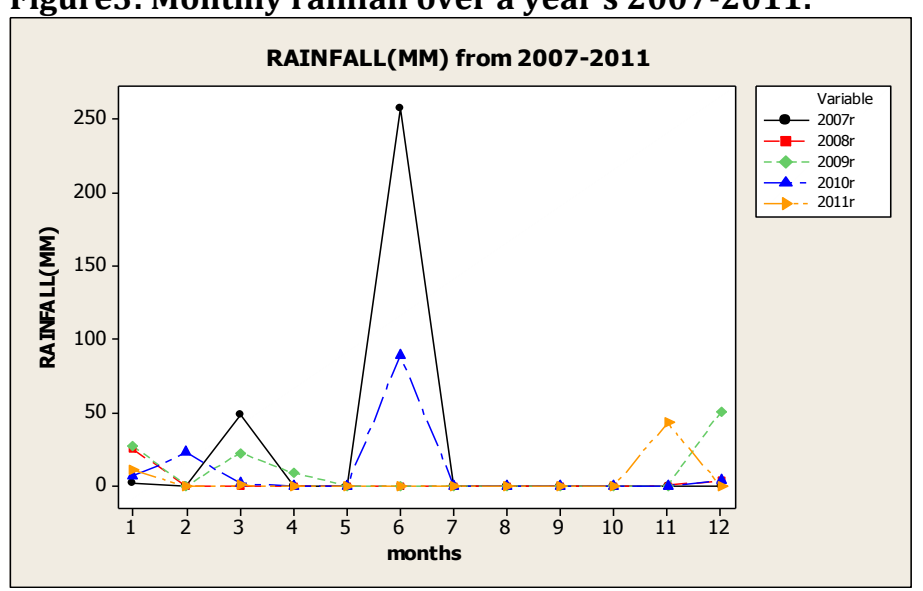

The purpose of the transfer function modeling are to identify and to estimate the transfer function,(B), and the noise model for $\eta_{t}$ based on the available information of the input series $x_{t}$ and the output series 
$\mathrm{w}_{\mathrm{t}}$. The major difficulty is that $\mathrm{x}_{\mathrm{t}}$ and $\mathrm{w}_{\mathrm{t}}$ are finite and the transfer function contain an infinite of coefficients. To alleviate this difficulty, $v(B)$ can be expressed in a rational form:

$v(B)=\frac{w_{s}(B) B^{b}}{\delta_{r}(B)}$

Where, $\mathrm{w}_{\mathrm{s}}(\mathrm{B})=\mathrm{w}_{0}-\mathrm{w}_{1} \mathrm{~B}-$

$\ldots-\mathrm{w}_{\mathrm{s}} \mathrm{B}^{\mathrm{s}}$ and $\delta_{\mathrm{r}}(\mathrm{B})=1-\delta_{1} \mathrm{~B}$

And $b$ is delay parameter representing the actual time lag that elapses the impulse of the input variable produced an effect on the output variable. For a stable system the roots of $\delta_{\mathrm{r}}(\mathrm{B})$ are assumed to be outside of the unit circle. The general procedure to identify the transfer function model can be described as follows:

A. Prewritten the input series

$\alpha_{\mathrm{t}}=\frac{\phi_{x}(B)}{\theta_{x}(B)} X_{t}$

Where $\alpha_{\mathrm{t}}$ is a white noise with mean zero and variance $\sigma^{2} \alpha_{\text {. }}$

B. Calculate the filtered output series. That is transform the output series $w_{t}$ using the above prewhitening model to generate the series $\beta_{t}$, where

$\beta_{\mathrm{t}}=\frac{\phi_{x}(B)}{\theta_{x}(B)} X_{t}$

C. Calculate the cross-correlation function (CCF) between $\alpha_{\mathrm{t}}$ and $\beta_{\mathrm{t}}$, to estimate $\mathrm{v}_{\mathrm{k}}$ :

$\hat{v}_{k}=\frac{\widehat{\sigma}_{B}}{\widehat{\sigma}_{\alpha}} \hat{\rho}_{\alpha \beta}(K)$

The signification of the CCF is tested by comparing with its standard deviation(n-K) $)^{1 / 2}$

The values of $b, r$ and $s$ are identified by observing the form of the CCF).

D. Preliminary estimation of the transfer function is obtained by nonlinear regression:

$v(B)=\frac{\widehat{W}_{S}(B)}{\widehat{\delta}_{r}(B)} B^{b}$

E. Compute noise series. Once preliminary estimate for the transfer function is obtained, noise series is computed as follows:

$\hat{\eta}_{t}=w_{t}-\frac{\widehat{w}_{S}(B)}{\widehat{\delta}_{r}(B)} B^{b} X_{t}$

F. Identify the noise model. Based on the sample ACF and PACF of residual the following structure is identified:

$\hat{\eta}=\frac{\theta(B)}{\phi(B)} a_{t}$

G. Full model estimation. Nonlinear regression method is used to conduct estimation for the full model:

$\mathrm{w}_{\mathrm{t}}=\frac{\widehat{\omega}(B)}{\hat{\delta}(B)} X_{t-b}+\frac{\hat{\theta(B)}}{\hat{\phi}(B)} \hat{a}_{t}$

$\mathrm{H}$. Compute residuals. If residuals the assumption of independent, normality, and constant variance, and also if all the parameters are significant, then the obtained model is the appropriate transfer function model. If this is not the case, then the processes start from step (1) over again, until a satisfactory model is developed.

\section{Analysis and Conclusion}

We considered the following functional form of the transfer function for analysis.

$\mathrm{z}_{\mathrm{t}}=\mu+\frac{C w(B)}{\delta(B)} B^{\mathrm{b}} \mathrm{Z}_{\mathrm{t}}(\mathrm{x})+\eta_{\mathrm{t}}$

where $\mathrm{z}_{\mathrm{t}}$ represent the stationary $\mathrm{y}_{\mathrm{t}}$ that was $\log$ transform water use and $\mathrm{z}_{\mathrm{t}}{ }^{(\mathrm{x})}$ represent the stationary $\mathrm{x}_{\mathrm{t}}$ which is the matrix with rainfall and temperature as columns. $\mathrm{C}$ is an unknown scale parameter,$\eta_{\mathrm{t}}$ represent the error component, $\mathrm{b}$ is the number of period the input series $\mathrm{x}_{\mathrm{t}}$ begins to affect the output series $y_{t}$ and equal the lag where we encounter the first spike in the sample cross correlation(SCC) , $\mu$ is the constant term, $\mathrm{w}(\mathrm{B})=\left(1-\mathrm{w}_{1} \mathrm{~B}-\mathrm{w}_{2} \mathrm{~B}^{2}-\ldots \ldots \ldots \ldots-\mathrm{w}_{\mathrm{s}} \mathrm{B}^{\mathrm{s}}\right)$ is called the $\mathrm{z}_{\mathrm{t}}{ }^{(\mathrm{x})}$ operator of order $\mathrm{s}$ and $\delta(B)=(1-$ $\left.\delta_{1} \mathrm{~B}-\delta_{2} \mathrm{~B}^{2}-\ldots \ldots \ldots-\delta_{\mathrm{r}} \mathrm{Br}\right)$ is called $\mathrm{z}_{\mathrm{t}}$ operator of order $\mathrm{r}$. We initially identified four of transfer function models. The models and the estimates of the parameters along with $\mathrm{p}$ values of these models are given below

Model 1:P= (12) $\mathrm{Q}=(12)=$ The model of natural $\log$ of water distribution has AR(12) and MA(12)

Table 1: The parameter estimates and $p$ values

\begin{tabular}{lll}
\hline Parameter & Estimates & p-value \\
\hline $\mathrm{MU}=\mu$ & 0.0074106 & 0.4184 \\
$\mathrm{MA} 1,1=\Theta_{1,12}$ & 0.16380 & 0.7996 \\
$\mathrm{AR} 1,1=\phi_{1,12}$ & -0.14845 & 0.8184 \\
\hline
\end{tabular}




\begin{tabular}{lll}
\hline $\mathrm{C}_{1}$ (temp) & 0.0033910 & 0.4487 \\
$\mathrm{C}_{2}(\mathrm{RF})$ & -0.0007461 & 0.2398 \\
\hline
\end{tabular}

Model 2:Q=(12)=the model of the natural log of water distribution that has $\mathrm{MA}(12)$

Table 2: The parameter estimates and $p$ values

\begin{tabular}{lll}
\hline Parameter & Estimation & p-value \\
\hline $\mathrm{MU}=\mu$ & 0.0070069 & 0.4289 \\
$\mathrm{MA} 1,1=\Theta_{1,12}$ & 0.29640 & 0.0939 \\
$\mathrm{C}_{1}(\mathrm{temp})$ & 0.0034585 & 0.4324 \\
$\mathrm{C}_{2}(\mathrm{RF})$ & -0.0006932 & 0.2483 \\
\hline
\end{tabular}

Model $3: Q=(1,12)=$ the model of natural log of water distribution that has $\operatorname{MA}(1,12)$

Table 3: The parameter estimates and $p$ values

\begin{tabular}{lll}
\hline Parameter & Estimates $\mathbf{w}$ & p-value \\
\hline $\mathrm{MU}=\mu$ & 0.0063 & 0.3778 \\
$\mathrm{MA} 1,1=\theta_{1}$ & 0.2512 & 0.1281 \\
$\mathrm{MA} 1,2=\theta_{1,12}$ & 0.2420 & 0.1439 \\
$\mathrm{C}_{1}($ temp) & 0.0028 & 0.5606 \\
$\mathrm{C}_{2}(\mathrm{RF})$ & -0.0006632 & 0.2689 \\
\hline
\end{tabular}

Model $4: P=(1,12) Q=(1,12)=$ the model of the natural $\log$ of water distribution that has $\operatorname{AR}(1,12)$ and $\operatorname{MA}(1,12)$

Table 4: The parameter estimates and $p$ values

\begin{tabular}{lll}
\hline Parameter & Estimation & p-value \\
\hline MU $=\mu$ & 0.0075506 & 0.1282 \\
MA1,1 $=\theta_{1}$ & 0.95198 & $<.0001$ \\
MA1,2 $=\theta_{1,12}$ & 0.04802 & 0.7762 \\
AR1,1 $=\boldsymbol{\phi}_{1}$ & 0.56200 & 0.0184 \\
AR1,2 $=\boldsymbol{\phi}_{1,12}$ & -0.11588 & 0.5685 \\
NUM1 $=C_{1}$ & 0.0038458 & 0.4366 \\
NUM2 $=C_{2}$ & -0.0009301 & 0.1626 \\
\hline
\end{tabular}

From the tables 1 to 4 it is very clear that first three models have all the estimates non- significant . But in model 4 the moving average one and autoregressive one at no-seasonal level are significant at 5\% level. We therefore conclude that model 4 is the best model for forecasting. The form of this model would be as below.

$\mathrm{y}_{\mathrm{t}}=\mu+\mathrm{C}_{1} \mathrm{Z}_{\mathrm{t}}(\mathrm{x} 1)+\mathrm{C}_{2} \mathrm{Z}_{\mathrm{t}}(\mathrm{x} 2)+\frac{\left(1-\theta_{1}-\theta_{1,12}\right)}{(1-\phi 1-\phi 1,12)} a_{t}+\mathrm{n}_{\mathrm{t}}(3.2)$

This model was then used to make monthly water use forecasts for one year ahead and these out of sample forecasts were used to assess the model by mean absolute deviation (MAD), mean square error (MSE) and mean absolute percent error (MAPE). All of these measures had reasonably small values which were $0.105,0.013$ and $1.37 \%$ respectively. More over the graph of cross-correlation between water distribution and average temperature showed a spike at lag $(-1)$ that indicate the amount of water distribution consume in one month is affected by previous month of average temperature. While the graph of cross-correlation between water distribution and average rainfall showed that there is a spike at lag zero that indicate the amount of water distribution consumed in the one month is affected by the rainfall on the same month. 


\section{References}

Agthe, D. E. \& Billings, R. B. (1980). Dynamic Models of Residential Water Demand. Water Resource Research, 16(3), 476-480.

Al-Oaimri \& Al-Hadrami (2013). Time Series Analysis of Domestic Water Demand in Muscat, DOMAS Project Report.

Bruce, L. B. \& O'Connell, R. T. (1993). Forecasting and Time Series and applied approach, Third Edition, Miami University.

Hutton, S. (2003). Saving the future - Water in Oman. Oman Economic Review.

Khtri, K. B. \& Vairamoorthy, K. (2007). Water Demand Forecasting for the City of the Future against the Uncertainties and the Global Change Pressures. Case of Birmingham. EWRI/ASCE: 2009, Conference: Kansas, USA May 17-21

Nazario, D. R. B. (1993). Prediction of Water Use in Puerto Rice'. Technical Report, Office of Water Resources Research, US Department of Interior Washington.

Ministry of national economy. Statistical Year Book. (2006 - 2010). Ministry of national economy in Sultanate of Oman.

Maidment, D. R., Miaou, S. P. \& Crawford, M. M. (1985). Transfer Function Model of Daily Urban Water Use. Water resource research, 21(4), 425-432. 